\title{
Enhancing creativity in activity-based offices: A critical incident study of knowledge workers
}

\author{
Sepideh Yekanialibeiglou ${ }^{1} \odot$ | Halime Demirkan ${ }^{1} \quad$ Leif Denti ${ }^{2}$
}

${ }^{1}$ Faculty of Art, Design and Architecture, Department of Interior Architecture and Environmental Design, i. D. Bilkent University, Ankara, Turkey

${ }^{2}$ Department of Psychology, University of Gothenburg, Göteborg, Sweden

\section{Correspondence}

Sepideh Yekanialibeiglou, Faculty of Art, Design and Architecture, Department of Interior Architecture and Environmental Design, i. D. Bilkent University, 06800 Ankara, Turkey.

Email: sepideh@bilkent.edu.tr
This study investigated the effects of activity-based offices (ABOs) on individual and group creativity. Adopting an interactionist perspective, we extended the theoretical framework of creative knowledge environments to find the link between $A B O$ s and the concept of creative spaces. We employed the critical incident technique and collected data through interviews and participant observation methods for the case studies of three ABOs. The results show that privacy, noise level, and a distractionfree environment were the main factors supporting employees' individual creativity, as were open spaces with zones for different levels of noise and private enclosed spaces. For group creativity, the significance of providing suitable equipment and furniture in $\mathrm{ABO}$ s was observed-collaborative and disengaged spaces were found to be the recurring spaces for group creativity. Additionally, employee preferences were noted as an important component to consider when looking at environmental features, types of spaces and types of creative activities in creativity-enhancing ABOs.

\section{KEYWORDS}

activity-based offices ( $A B O s$ ), creative knowledge environments (CKEs), creative spaces, employee creativity, interactionist theory, office design

\section{1 | INTRODUCTION}

Creativity strengthens organizations' capabilities to react to new opportunities, adapt to change, and compete (Klein \& Sorra, 1996; Pitta et al., 2008). Creativity can be considered as the ability to generate novel and useful ideas to solve new and ill-defined problems (Amabile et al., 1996; Brophy, 1998; Feist, 1998; Hemlin et al., 2008; Mumford et al., 2002). In the creative problem solving process, group creativity is considered a collaborative effort involving interaction and coordination with another individual or group (Paulus et al., 2012). Early interactionist theory of organizational creativity developed by Woodman et al. (1993) emphasizes that creativity results from interactions between individuals and their working conditions at different organizational levels (individual, group, and organization). Creativity at the individual level results from antecedent conditions, cognitive styles and abilities, personality (e.g., locus of control), motivation, social inspirations (e.g., rewards), relevant knowledge, and contextual impacts (e.g., physical environment) (Anderson et al., 2014). The interaction between an individual and a situation is repeated at every analysis level (Woodman et al., 1993). Interactions between individual creative behaviour, group members (e.g., group composition), characteristics (e.g., norms, size), processes, and contextual influences lead to group creativity (Anderson et al., 2014). The present study took an interactionist view of human organization, which implies that the interplay between individuals and environment must be considered to fully understand creativity. Early research found that physical environment affects interaction patterns and employees' creativity (Oldham et al., 1995); however, few studies have investigated its impact on employee creativity in office settings (Hoff \& Öberg, 2015; Meinel et al., 2017). Therefore, further research on this aspect is necessary (Oldham \& Baer, 2012)-for this, adopting an interactionist perspective is important, as a full understanding of environmental contexts' effects on creativity is incomplete without it (Zhou \& Hoever, 2014). Given the lack of empirical evidence (Batey et al., 2021) and repeated calls for research in previous studies (Dul et al., 2011; Hemlin et al., 2008; Oldham \& Baer, 2012; Paletz, 2012), how the physical environment directly and indirectly influences creativity and its interactional mechanisms require further exploration. 
This study focused on knowledge-intensive workplaces. The theoretical framework of creative knowledge environments (CKEs) by Hemlin et al. (2008) was chosen, as it fits well into the interactionist perspective and is better suited to study knowledge workers' creativity. CKEs suggest that creativity study in the workplace should integrate factors at different levels of organizations, aside from contextual factors. These factors interact in predicting individual, group, organizational, and interorganizational creativity. Thus, both frameworks posit that creativity results from complex person-situation interactions.

With digital advancements and development of mobile communication technology, the spatial structure of knowledge-intensive organizations has changed, and alternatives to traditional office concepts have emerged, such as flexible offices, the trendiest being activity-based offices (ABOs). ABOs provide employees a variety of spaces depending on their activity type (Appel-Meulenbroek et al., 2011) and preferences (Wohlers \& Hertel, 2017). An increasing number of organizations worldwide are adopting ABOs (Chafi et al., 2020). Therefore, it is important to examine how they affect employee outcomes (Hoendervanger et al., 2018). While cultivating creativity in offices with new ways of working is important for organizational success, no studies have focused on creativity and ABO design's intersection (Nanayakkara et al., 2021).

Certain types of spaces and features in office environments, called "creative spaces," enhance creativity (Lee, 2016; Thoring et al., 2018). However, there is a gap in our current understanding of whether $\mathrm{ABO}$ s promote employee creativity and can be classified as creative spaces. Based on Thoring et al.'s (2018) creative space definition, for our study, we classified $A B O$ spaces as creative if they supported employees' creative activities. This is a point of concern in many organizations, since they aim to cultivate employee creativity through creativity-stimulating physical and social environments (Meinel et al., 2017). According to Thoring et al. (2018), many studies have not provided examples of actual case studies. Therefore, the typology of creative spaces remains unclear.

Considering the abovementioned research gaps, an exploratory and inductive study of $\mathrm{ABO}$ s should investigate the relationship between physical environment and employees' creative activities. This study aims to contribute to the interactionist theory within the scope of the CKE framework to understand the physical environment's role in $\mathrm{ABOs}$ as knowledge-intensive and flexible workplaces with a multilevel (individual and group) creativity analysis. The practical relevance relates to optimizing the creativity-enhancing aspects of $\mathrm{ABO}$ s by outlining supporting and hindering features. The study findings can improve environmental designers' and planners' understanding of $A B O$ spaces to promote employee creativity.

\section{2 | THEORETICAL BACKGROUND}

\section{1 | The interactionist perspective and physical work environment}

The joint literature on creativity and physical environment includes few studies taking an interactionist approach. Evans et al. (Evans et al., 1994, op cit. Leather et al., 2003) analysed the interaction between the physical and social environments and proposed that any feature of the physical environment can directly influence outcomes and/or interact with psychosocial work elements. Vithayathawornwong et al. (2003) proposed that the physical work environment does not directly influence creativity, but enables the social work environment to do so. Dul et al. (2011) investigated the joint effects of creative personality and social and physical work environments on individual creativity. They found that the physical work environment influenced creativity slightly less than the social work environment did. However, they did not find any interaction between the two environments.

None of these studies have examined the environment's effects on group creativity. Oldham and Baer (2012) and Zhou and Hoever (2014) also called for more studies to address the effects of the physical and social environments on group creativity. In addition, all of these studies were conducted in traditional offices where employees worked at allocated workstations; yet, they did not arrive at a consensus on the physical environment's direct and indirect interaction with other contexts in influencing creativity. In the ABO context, where employees have a flexible workstation, the interaction between individuals and their work environment is different. This is because employee preferences play a more important role in flexible workplaces than in traditional offices with fixed workstations (Chafi et al., 2020). Some studies have suggested that diverse office spaces and work environments could increase creativity in terms of promoting interactions between employees and their environment (Ilozor et al., 2002). Therefore, examining the role of the physical environment on employee creativity in ABOs and its interactional mechanisms is an important topic explored in this study. More details about $\mathrm{ABO}$ s and the types of creative activities in these knowledgeintensive workplaces are provided in the subsequent sections.

\subsection{Activity-based offices and creative spaces}

In $\mathrm{ABO}$ s, open spaces are the central areas for work, enclosed backup ones provide space for private individual and group activities (Babapour Chafi \& Rolfö, 2019), and informal ones are used for employee socializing or rest. Rules are often set to guide employees regarding the proper use of spaces, such as a desk-sharing or speech policy. Creative spaces are categorized in the literature as private spaces (Thoring et al., 2018), collaborative spaces (Hoff \& Öberg, 2015; Lee, 2016; Meinel et al., 2017; Thoring et al., 2018), relaxing spaces (Hoff \& Öberg, 2015; Lee, 2016), and disengaged spaces (Hoff \& Öberg, 2015; Lee, 2016; Meinel et al., 2017; Thoring et al., 2018)-all these are also present in ABOs, but their potential to be classified as "creative" spaces in ABOs is unknown.

Private spaces are suitable for contemplation and concentration required for reading, writing, ideation, or phone/video calls (Thoring et al., 2018); collaborative spaces support group interactions and are usually equipped with low- and high-tech IT equipment to facilitate virtual meetings (Lee, 2016); relaxing spaces provide opportunities for 
rest and spontaneous thoughts (Meinel et al., 2017); and disengaged spaces provide opportunities for non-work-related activities in social and informal interactions (e.g., kitchen or café) or recreational spaces (e.g., table tennis room) (Meinel et al., 2017). According to Lee (2016), disengaged spaces have the strongest positive effect on creativitythe author also found that a balanced layout, low- and high-tech equipment, and spaces for ideation are three important features that support creativity.

In a literature review of 17 articles, Meinel et al. (2017) categorized office interior features having an impact on creativity in work environments, thus (1) spatial layout, (2) office elements (intangible and tangible), and (3) types of spaces. They found that most articles in the literature analysed the positive effects on individual creativity, with only three among these also examining the negative effects. Consistent with this deficiency, and from an interactionist perspective, Zhou and Hoever (2014) also noted this lack and suggested further research to examine the effects of both creativity-hindering and creativity-supporting features. Moreover, as Meinel et al. (2017) mentioned, further studies on multilevel (individual and group) analysis of creativity are needed. Additional details on individual and group creativity in $\mathrm{ABO}$ s are provided in the subsequent sections.

\section{3 | Creative activities}

New ways of working, such as flexible and agile work practices, have triggered a change in the working styles and activities of knowledge workers. Therefore, to determine the creativity-enhancing/hindering features of $A B O s$, we should first understand the different types of creative activities that take place in this environment. Tabak (2009) proposed a general classification of office activities and specified three categories: (1) nature of activities, (2) individual or group activities, and (3) planned or unplanned activities. De Been et al. (2015) suggested that concentration and formal and informal interactions were the most significant activities in knowledge-intensive workplaces (van den Berg et al., 2020). Whereas creativity is the generation of novel and useful ideas, often to solve problems, creative activities are the behavioural aspects of idea generation in the form of daily activities occurring in the workplace (Brophy, 1998; Ward, 2012). This study focuses on individual and group creative activities, classified under formal (work-related) and informal (non-work-related) (Hoff \& Öberg, 2015; Lee, 2016; Meinel et al., 2017; Thoring et al., 2018).

\subsection{1 | Formal and informal creative activities in the office}

Formal-individual activities mostly involve official and work-related tasks carried out by an individual in a formal setting. During the creative process, there are periods in which individuals need solitude for contemplation and concentration, which is required for individual ideation, reading, writing, or research. Improving concentration leads to "Eureka!"-like discoveries, enables an individual to come up with multiple solutions during problem solving, and cultivates creativity (Canestrari \& Marlowe, 2018). According to Stokols et al. (2002), environmental distractions at work can restrict employees' creativity by interfering with their concentration. In addition, Yekanialibeiglou and Demirkan (2018) found that privacy is important for employee individual creativity. A literature review reported that working in ABOs generally has a negative effect on employees' concentration (Engelen et al., 2018). Other findings have indicated that distractions tend to decrease after the organization adopts an ABO layout (see, e.g., Van der Voordt, 2004).

Informal-individual activities involve informal and non-official pursuits in informal settings. In the creative process, there are times when the brain needs to rest, to facilitate mind-wandering, to contemplate and form new connections. A break from work-related activities-for example, resting, taking a nap, or relaxing-can reduce stress levels and facilitate ideation (Steiner, 2006). Although recent studies have indicated the importance of having a dedicated space for relaxation/ rest in the workplace, there is little research on how the work environment affects employee relaxation (Hoff \& Öberg, 2015; Lee, 2016).

Formal-group activities involve participating in planned or unplanned official group tasks on work-related content while sharing knowledge. Group creativity occurs when two or more employees collaborate to explore new and useful ideas (Paulus et al., 2012). Despite the increasing prevalence of teams in the modern era, most previous studies have examined the effects of work environment only on individual creativity, and more studies are needed to fill this gap (Oldham \& Baer, 2012; Zhou \& Hoever, 2014). Group collaboration is a strong positive factor in CKEs. Group creativity and collaboration can occur during formal meetings, hybrid and digital meetings, seminars, workshops, or unplanned work-related meetings as formal-group activities. Some studies have reported that $A B O s$ have a positive impact on collaboration (Blok et al., 2012; Robertson et al., 2008) and communication (Blok et al., 2012). A literature review on the benefits of $A B O$ s for employees' health and work performance has shown that people engage in greater collaboration, communication, and knowledge exchange with a wider range of colleagues when they sit with those from other departments in open areas (Engelen et al., 2018). Contrastingly, some studies have reported that employees find it difficult to discuss confidential information in open spaces during collaborative activities (Babapour Chafi \& Rolfö, 2019; De Been et al., 2015). This characteristic of $\mathrm{ABO}$ can hinder employee creativity because it restricts the available pool of knowledge and slows down idea exchange.

Informal-group activities involve social gatherings for non-workrelated pursuits in informal settings-such as playing billiards, informal interactions, and spending time with others during coffee breaks or lunch. These activities are thought to enhance employee bonding and improve group creativity (Hoff \& Öberg, 2015). Previous studies have suggested that employees exchange more ideas and knowledge during informal-group activities than during formal meetings (Wensley, 1998). According to Engelen et al. (2018), working in ABOs positively influences employees' social activities and informal interactions. However, study of this topic is still rare. 
Consequently, considering the shortcomings in the literature, it is important to conduct an investigation from both theoretical and practical perspectives; this is necessary to fill the aforementioned gaps in the joint research on office design by focusing on ABOs and creativity. In an attempt to address these issues and better understand employee creativity in $\mathrm{ABO}$, the present study is positioned by integrating the following aspects to determine how (1) the $A B O$, as a knowledge-intensive and flexible office concept, (2) supports and/or hinders employees' creative activities at the (3) individual and group levels and in formal and informal settings, by adopting (4) an interactionist perspective (5) in the CKE framework. The main objective of this study is to determine the types of spaces and interior features of $\mathrm{ABO}$ s that are important for the four types of creative activities, how these features support and/or hinder these activities, and, accordingly, whether $\mathrm{ABO}$ s can be classified as creative spaces. The research questions formulated for this study are as follows:

RQ1: How do types of spaces and interior features of $A B O$ s act as possible means to support or hinder individual-formal/informal creative activities?

RQ2: How do types of spaces and interior features of $A B O s$ act as possible means to support or hinder group-formal/informal creative activities?

\section{3 | METHODOLOGY}

\section{1 | Case study}

The case study approach was adopted to investigate three organizations in Sweden in 2019. Case studies provide comprehensive information (Merriam, 2009) by using multiple sources when collecting data (Creswell, 2013). Our research questions, which focus on how ABOs influence employee creativity, required a deep contextual understanding that the case study approach adequately fulfilled. Case studies are generally conducted in a natural setting where the researcher has limited control over events (Yin, 2018). In the present study, this approach was appropriate for an in-depth analysis and understanding of $A B O s^{\prime}$ potential to support or hinder creativity and its association with creative spaces. In addition, to reduce the aforementioned research gap, it was necessary to gain insights into real cases when studying creative spaces (Thoring et al., 2018).

A non-probability purposive sampling method was used to select the three international companies in Gothenburg, Sweden. The main selection criterion was the types of spaces and features they possessed, which were designed to modernize employees' ways of working and encourage interaction; the employees had moved to the ABOs more than 6 months before the interviews were conducted. This was important because, sometimes, employees form a negative first impression after moving to their $\mathrm{ABO}$, and it takes time to adapt to the new environment (Babapour Chafi \& Rolfö, 2019). Another important criterion was that these companies' work was mainly knowledge-intensive, complicated, and competitive, and hence, creativity was necessary for success. In addition, these cases were considered as typical (Denscombe, 2014) because the companies' buildings were located in a city and considered overcrowded, leading to higher space efficiency in the ABOs (Rolfö, 2018).

All three companies had an open and a half-open space with silent, semi-silent, and collaboration zones, and enclosed "back-up spaces," enclosed collaborative spaces, informal spaces for relaxing, and disengaged spaces, such as kitchen/lounge. None of them had spaces for recreation or balconies. Therefore, all were considered to sufficiently embody the characteristics of $A B O$ environments. Case 1 was the headquarters of a research institution, with a capacity for up to 50 employees; the headquarters was relocated to an $A B O$ 2 years before the study. Case 2 was an office run by 13 small organizations that help new and existing entrepreneurs to start and run businesses-the organizations were from different locations and had started working together in an $\mathrm{ABO}$ around one and a half years before the study; it had the capacity to support up to 60 employees. Case 3 was the headquarters of a Swedish multinational manufacturing company, which had an open office layout; it had moved to its new $A B O$ building 1 year prior to the study and had a capacity for up to 250 employees.

\section{2 | Design}

The study was conducted in two parallel phases, with different tools and analysis methods employed during each. Phase 1 involved a qualitative data collection approach through an interview with a process manager in each company to acquire general information about it. Then, interviews were conducted with knowledge workers using the critical incident technique (CIT) (Flanagan, 1954). A qualitative study approach was adopted because it provides an in-depth understanding of how $\mathrm{ABO}$ environments affect employees' creativity, and whether $\mathrm{ABO}$ s can be classified as creative spaces. CIT is a qualitative method that involves the study of significant situations of a specific activity as experienced by the participants (Hughes et al., 2007). The present study follows the definition suggested by Bitner et al. (1990): "A critical incident is an observable human activity that contributes to or detracts from the general aim of the activity in a significant way" (p. 73). Since the focus of this study was on creative activities, the CIT prompted the participants to focus on actual creative incidents in the office, instead of providing general opinions on office environments and creativity (Serenko, 2006). The participants were asked to recall one or several recent incidents they had been involved in (Hughes et al., 2007) and explain the aspects that supported or hindered their creativity in each. Phase 2 involved an observational study quantifying space usage and the number of activities in each space type as supplementary data. Then, the findings of the primary and supplementary data collection were compared and integrated (see Figure 1). 


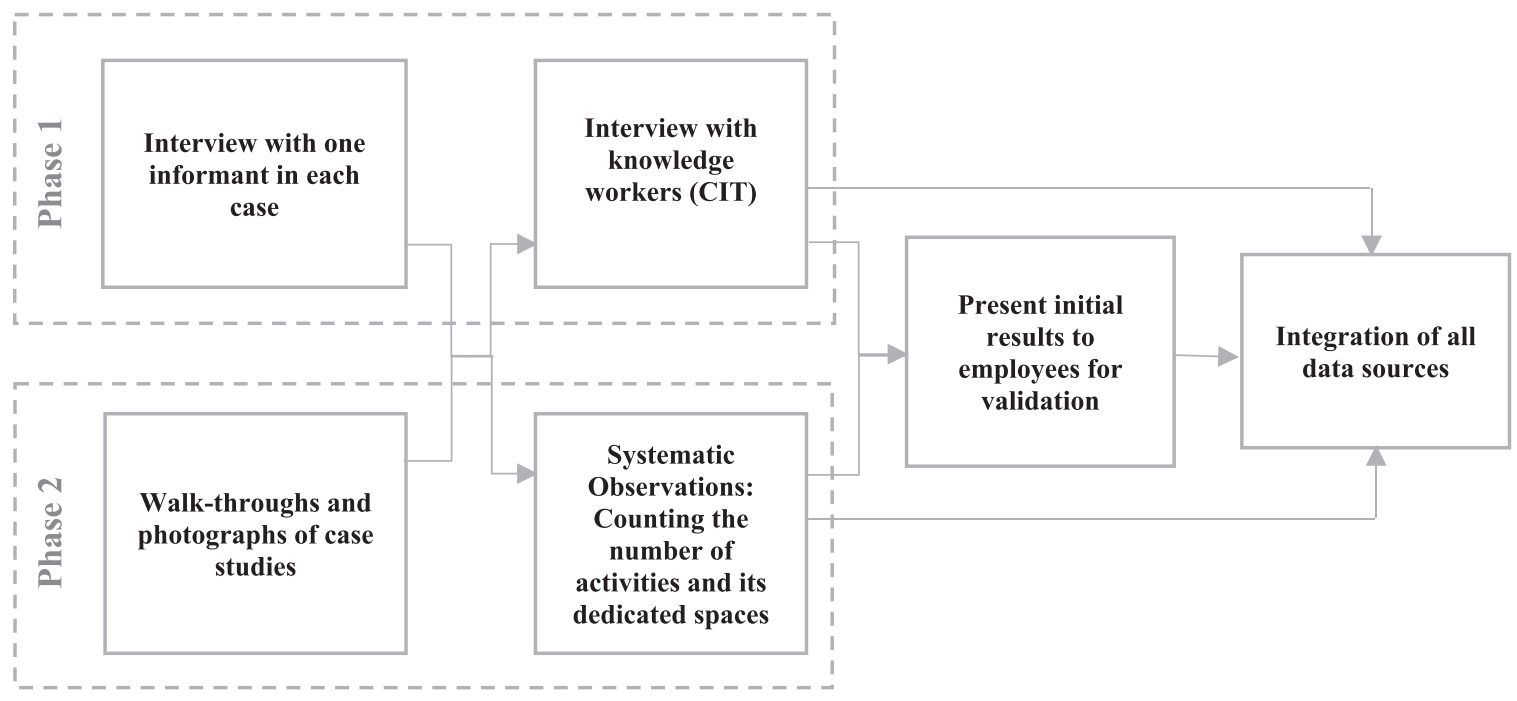

FIGURE 1 Research design, an overview of two phases of the study

\section{3 | Participants}

Fifty knowledge workers were selected on a self-selection basis from those working in the three ABOs in Gothenburg, Sweden. One week before the interview, all participants were informed by e-mail about the study: that it was academic research independent of their organization and that their identity would remain confidential. Participation in the interview was voluntary and offered through a sign-up list provided by us. The majority of participants had university degrees-46 per cent had a master's degree and 38 per cent had a bachelor's degree; the rest were high school graduates. Their educational backgrounds were diverse and included business, journalism, engineering, and human resources. There was a near even division in their proportion when it came to gender-52 per cent male and 48 per cent female. The average age was 42 years ( $S D=10.4$ years). A higher number had been working at their $A B O$ for 6 to 12 months (50 per cent), while 26 per cent had been there for less than 6 months and 24 per cent for 1 to 2 years. The average time spent working in the $A B O$ was 76 per cent of the workweek ( $S D=20.8)$.

\section{4 | Procedure}

The data collection process was conducted over 3 days in cases 1 and 2 and over a week in case 3 in 2019-individual interviews, observations, field notes, and photographic documentation. Each participant's interview took between 20 and 50 min. All participants provided consent for their interviews to be recorded.

\subsection{1 | Phase 1}

First, an interview was conducted with the process or staff manager in each company to gain insights into the $A B O$ environment, specifications of the spaces, and design process. This supplementary information provided us better knowledge of each case study and overall details about the environment and activities needed for the $\mathrm{CIT}$ interview procedure with knowledge workers. All interviews were conducted in English. Under the CIT, the interviews were started by asking the participants to focus on and recall a recent incident (Hughes et al., 2007) through the question, "Please remember the last time you needed a space in your office for (1. individual concentration/focus, 2. relaxation, 3. team collaboration, and 4. social interactions) in the process of creativity" (creativity defined as the ability to generate novel and useful ideas to solve a problem) (Amabile et al., 1996). After recalling incidents of each type (1, 2, 3, and 4), the participants were asked to answer the following questions for each incident:

i. Which space type did you occupy for your creative purposes? How does it work?

ii. What were the most important interior features that supported your creative process? How?

iii. What were the most important interior features that hindered your creative process? How?

iv. Were you able to come up with novel ideas or solve the problem?

\subsection{2 | Phase 2}

The first day of site visits began with walk-throughs and photographing of the area to gain insights into the $A B O$ environment and spaces. For a complete understanding of the use of $A B O$ spaces, we observed the types of creative activities, number of people using each space, and overused and ignored spaces in each case. This provided some supplementary information about workstation availability, the flow of employees using $\mathrm{ABO}$, and the locations for different 
types of activities. As seen in Figure 2, these data were marked on the ABOs' architectural drawings.

During the regular workweeks, the first author conducted 11 rounds of observation in the morning, around lunchtime, and in the afternoon on different days of the week. Each round was completed by walking in the same direction, to cover and observe all workstations and workspaces, and marking the different types (formal and informal) and levels (individual and group) of creative activities on an architectural drawing of the $\mathrm{ABO}$. Observations were conducted in four rounds for cases 1 and 3 and three rounds (due to practical circumstances) for case 2 .

\section{5 | Data analysis}

From the interviews, all of which were fully transcribed, 214 incidents (174 specific, 40 general) were collected from the 50 participants. On average, each participant recalled 4.28 incidents $(S D=0.5)$. The data were separated into four bodies according to the four main types of creative activities; then, each body was coded separately. Thematic analysis was conducted by adopting Braun and Clarke's (2006) category system. The first step was to familiarize with the data and insert the descriptions of the collected incidents into a matrix with four separate columns for each interview question: the space for the activity, its supporting and hindering features, and consequences. Each column was coded and classified into new subcategory columns according to their similarities in the second step. The third step was to merge the subcategories into larger, conceptually meaningful categories: (1) disengaged space, (2) collaborative space, (3) relaxing space,
(4) open space, and (5) private space for the first column on the types of spaces; (1) intangible elements, (2) tangible elements, and (3) spatial layout (categories adopted from Meinel et al., 2017) for the second and third columns, including supporting and hindering features; and "Yes" or "No" for the last column. The fourth step was to check internal homogeneity and external heterogeneity to determine if the codes were coherent in each category and the categories were distinguishable from each other. Then, inter-rater reliability was calculated to test the reliability of coding and categorization (Lombard et al., 2002).

Only one author was involved in the coding. As Campbell et al. (2013) explained, most qualitative data in many research projects are coded by a single coder. To obtain the intercoder reliability, an additional person was enrolled to code a sub-sample of the data (15 per cent, depending on the size of the data set, is considered typical) (O'Connor \& Joffe, 2020). This sub-sample was randomly selected to ensure the representativeness of the entire data set. The kappa value for intercoder reliability was substantial for formal-individual activities $(\kappa=0.74)$ and formal-group activities $(\kappa=0.79)$ and almost perfect for informal-group and informal-individual activities $(\kappa=0.90$ and $\kappa=0.84$, respectively).

While analysing the observational data, the number of people who used each space type (e.g., private space) for each activity type (e.g., formal-individual: concentrating on reading, writing) was observed and recorded in an Excel sheet. This was done for all three cases.

Finally, data collected from all supplementary sources, such as observations and field notes, as well as the feedback collected from the participants in each case by presenting the initial findings to them,

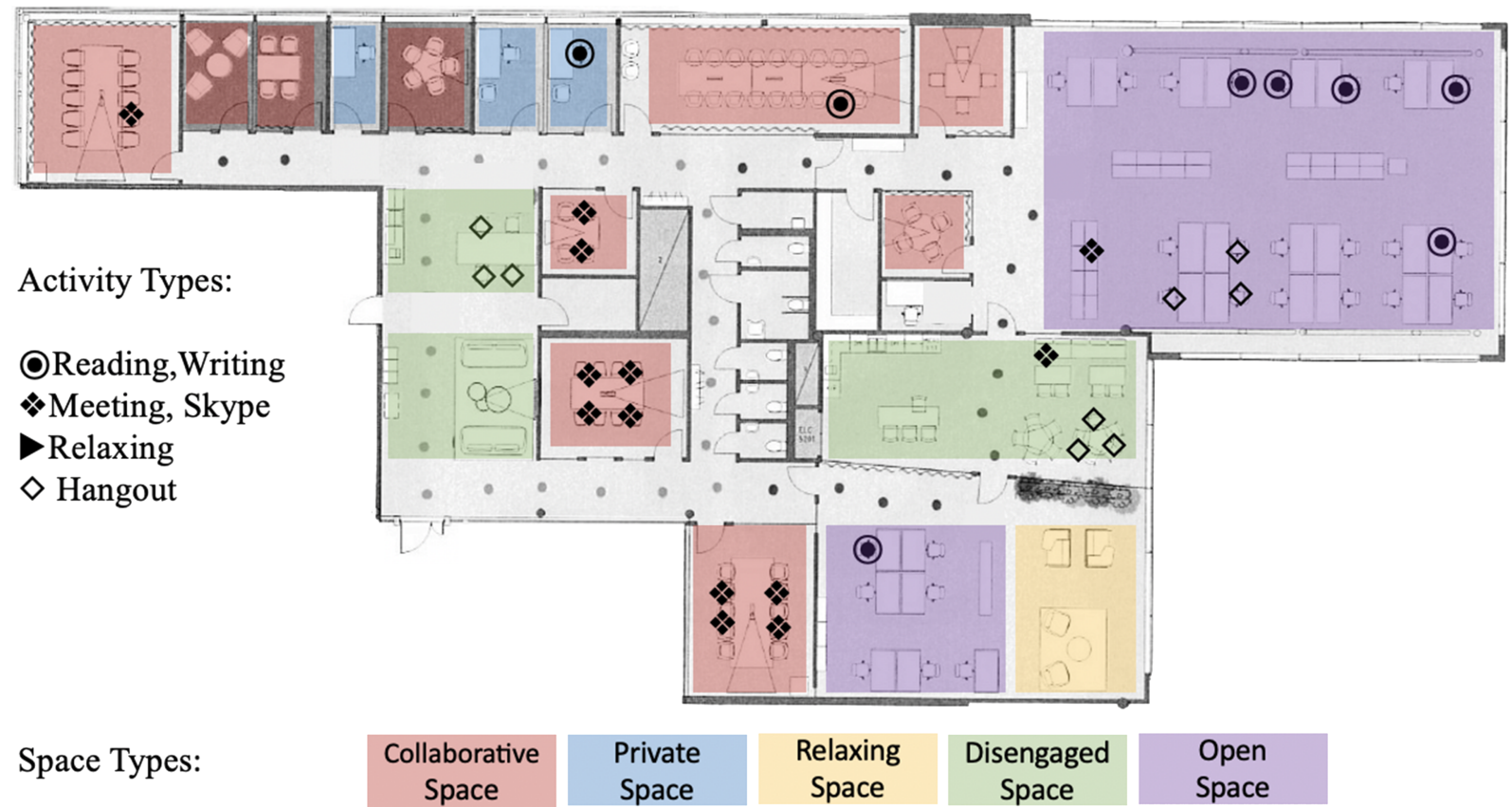

FIG URE 2 Space usage of employees during activities based on one round observation in one of the cases (observation session 4, 15:30 to $16: 10, n=30$ ) [Colour figure can be viewed at wileyonlinelibrary.com] 
were used to validate, match, and interpret the results of the major data collection (CIT interviews) and develop an overall discussion and conclusion. More specifically, the activities taking place in each space were observed and used to interpret, integrate, and compare the results of the $\mathrm{CIT}$ interviews.

TAB LE 1 Space types occupied for "formal-individual" creative activities in the ABOs $(n=50$, total incidents $=56$ )

\begin{tabular}{|c|c|}
\hline Categories of spaces & Frequency (\%) \\
\hline 1. Open space & $36(64 \%)$ \\
\hline (a) Semi silent & 23 \\
\hline (b) Silent/library & 13 \\
\hline 2. Private space & $12(21 \%)$ \\
\hline (a) Single room & 12 \\
\hline 3. Collaborative spaces & $6(11 \%)$ \\
\hline (a) Bookable & 4 \\
\hline (b) Not bookable & 2 \\
\hline 4. Disengaged space & $1(2 \%)$ \\
\hline (a) Kitchen & 1 \\
\hline 5. Out of office & $1(2 \%)$ \\
\hline (a) Home & 1 \\
\hline Total & $56(100 \%)$ \\
\hline
\end{tabular}

\section{4 | RESULTS}

The results presented below mainly refer to the findings from the CIT interviews regarding the ABO's impact on individual and group creativity, as well as observations used as supplementary data to understand the actual use of spaces for interpretive purposes.

\subsection{Impact of space type and interior features on creativity: Formal-individual activities}

In all, 56 (specific $=49$, general $=7$ ) incidents for formal-individual activities in the different spaces (Table 1) were collected (average incident for each participant $=1.1, \mathrm{SD}=0.5$ ). The space type used the most for these was open space (64 per cent), followed by private space (21 per cent).

Table 2 describes interior features that supported or hindered formal-individual activities. Among the supporting interior features, the topmost category is spatial layout (43 per cent), whose main subcategory is social distraction-free (16 per cent): "I sat there (the library), and nobody found me, (...) When I sit there, colleagues reach out to me via email, but when I sit in a private room, they come in person, which is distracting when I am focusing on a problem."

TAB LE 2 Interior features supporting or hindering "formal-individual" creative activities in the ABOs $(n=50$, total incidents $=56)$

\begin{tabular}{|c|c|c|c|c|c|}
\hline & \multirow{2}{*}{$\begin{array}{l}\text { Supporting interior } \\
\text { features }\end{array}$} & \multirow[b]{2}{*}{$\begin{array}{l}\text { Frequency (\% of total supporting } \\
\text { features) }\end{array}$} & & $\begin{array}{l}\text { Hindering interior } \\
\text { features }\end{array}$ & \multirow[b]{2}{*}{$\begin{array}{l}\text { Frequency(\% of total hindering } \\
\text { features) }\end{array}$} \\
\hline & & & & Category/subcategory & \\
\hline 1 & Spatial layout & $53(43 \%)$ & 1 & Tangible office elements & 17 (38\%) \\
\hline (a) & Social distraction-free & $19(16 \%)$ & (a) & Equipment & $6(13 \%)$ \\
\hline \multirow[t]{3}{*}{ (d) } & Space openness & $10(8 \%)$ & (b) & Window/view (lack) & $4(9 \%)$ \\
\hline & & & (c) & Decoration and design & $4(9 \%)$ \\
\hline & & & (d) & Furniture & $3(7 \%)$ \\
\hline 2 & Tangible office elements & $36(30 \%)$ & 2 & Spatial layout & $15(34 \%)$ \\
\hline (b) & - Low-tech & & (d) & Space openness & $2(3 \%)$ \\
\hline (c) & Decoration and design & $8(7 \%)$ & & & \\
\hline (d) & Furniture & $4(3 \%)$ & & & \\
\hline 3 & $\begin{array}{l}\text { Intangible of office } \\
\text { elements }\end{array}$ & $33(27 \%)$ & 3 & $\begin{array}{l}\text { Intangible office } \\
\text { elements }\end{array}$ & $13(28 \%)$ \\
\hline (a) & Sound level & $26(21 \%)$ & (a) & Sound level & $8(18 \%)$ \\
\hline \multirow[t]{3}{*}{ (b) } & Light & $7(6 \%)$ & (b) & Light & $3(7 \%)$ \\
\hline & & & (c) & Air condition & $2(3 \%)$ \\
\hline & Total & $122(100 \%)$ & & Total & 45 (100\%) \\
\hline
\end{tabular}


Among the hindering interior features, tangible office elements is the topmost category (38 per cent), mainly referring to the lack/issue of equipment (13 per cent). Among the related complaints was the following: "We also have IT-related challenges and technical limitations. You need to spend time to unplug and plug the computer and connect it somewhere else. That's why I did not change my seat, but I could not concentrate this morning."

TAB LE 3 Space types occupied for "informal-individual" activities in the creative work process in the ABOs ( $n=50$, total incidents $=51$ )

\begin{tabular}{|ll}
\hline Categories of spaces & Frequency (\% of total incidents) \\
\hline 1. Disengaged space & $16(31 \%)$ \\
\hline (a) Kitchen/coffee area/sofa & 16 \\
\hline 2. Out of office & $11(21 \%)$ \\
\hline (a) Home/outdoor & 11 \\
\hline 3. Relaxing space & $10(20 \%)$ \\
\hline (a) Well-being room & 10 \\
\hline 4. Open space & $7(14 \%)$ \\
\hline (a) Semi-silent & 1 \\
\hline (b) Silent & 6 \\
\hline 5. Private space & $4(8 \%)$ \\
\hline (a) Single room & 4 \\
\hline 6. Collaborative space & $3(6 \%)$ \\
\hline (a) Non-bookable/bookable & 3 \\
\hline Total & $51(100 \%)$ \\
\hline
\end{tabular}

\subsection{Impact of space type and interior features on creativity: Informal-individual activities}

In all, 51 (specific $=30$, general $=21$ ) incidents related to informalindividual activities (Table 3) were collected (on average: 0.9, $\mathrm{SD}=0.3)$.

The space type most used for informal-individual activities such as relaxation is disengaged space (31 per cent); it was surprising that relaxing rooms were underused for this purpose. What some participants mentioned may explain why these rooms in the ABOs stayed empty: "It seems odd to go to relaxing rooms," or "It is very obvious that when you are in the relaxing room, you are not working."

Among the supporting interior features, spatial layout (52 per cent) is the topmost category, with privacy (36 per cent) emerging as the main subcategory (Table 4): "I was feeling stressed and went there for some calm; you can get some privacy there." Among the hindering interior features, tangible office elements (56 per cent) is the topmost category, referring to unsuitable design and uncomfortable furniture: "[The] relaxing room is not cozy; it is like a dentist waiting room."

\subsection{Impact of space type and interior features on creativity: Formal-group activities}

In all, 63 incidents (specific $=58$, general $=5$ ) related to formalgroup activities were collected, and on average, each participant recalled 1.28 incidents ( $S D=0.5$ ) (Table 5). The most used space type is collaborative space, with 86 per cent of all the incidents happening there.

TAB LE 4 Interior features supporting or hindering "informal-individual" activities supporting the creative process in the ABOs $(n=50$, total incidents $=51$ )

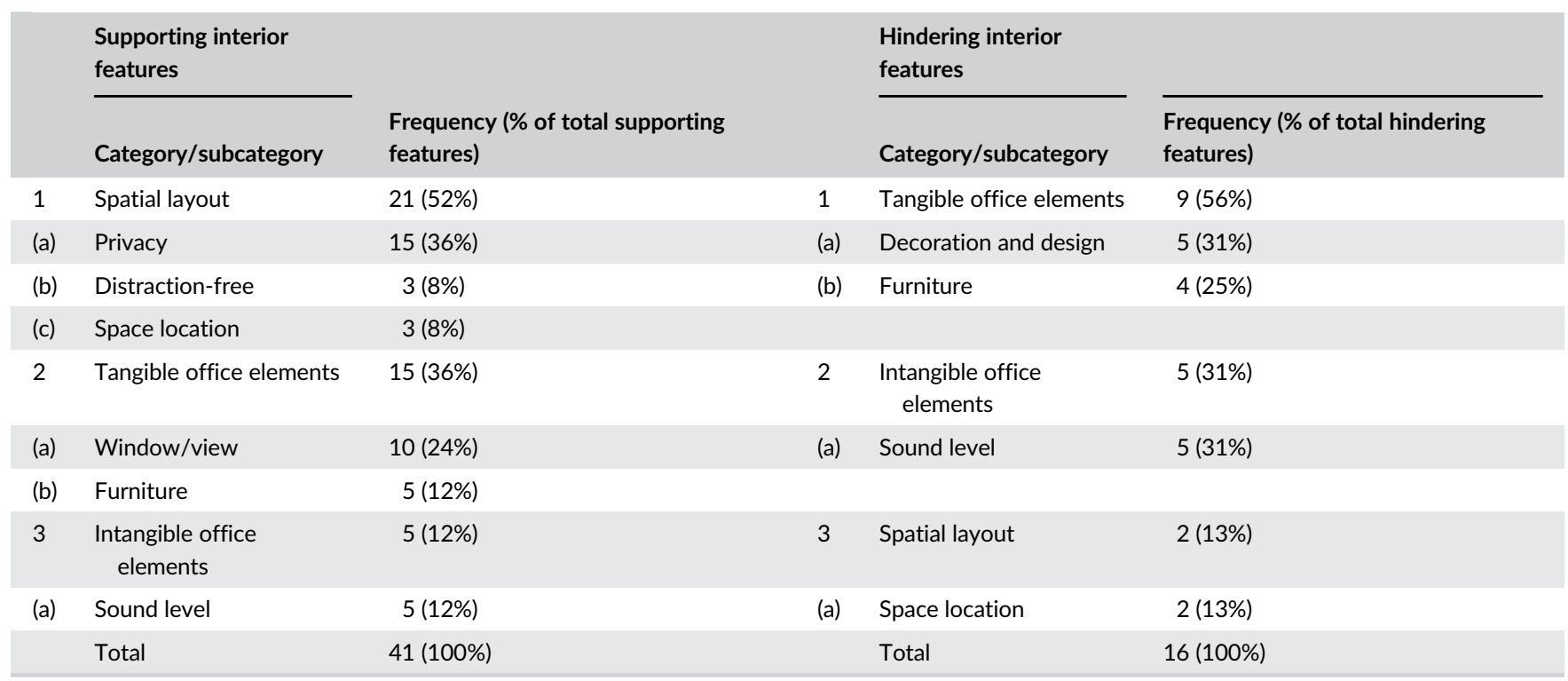


Among the supporting interior features, tangible office elements (52 per cent) is the topmost category, with office equipment (28 per cent) as its main subcategory: "[The] meeting room has a whiteboard for when creativity is required during meetings" (Table 6).

Among the hindering interior features, tangible office elements (63 per cent) is the topmost category, with an emphasis on the lack/ issues of some equipment (31 per cent): "There were some problems in connecting to the system because we did not know how to use the new system of virtual meeting rooms."

TAB LE 5 Space types occupied for "formal-group" creative activities in the ABOs ( $n=50$, total incidents $=63$ )

\begin{tabular}{|ll}
\hline Categories of spaces & Frequency (\% of total incidents) \\
\hline 1. Collaborative space & $54(86 \%)$ \\
\hline (a) Bookable & 39 \\
\hline (b) Non-bookable & 15 \\
\hline 2. Open space & $5(8 \%)$ \\
\hline (a) Collaboration zone & 5 \\
\hline 3. Private space & $2(3 \%)$ \\
\hline (a) Single room & 2 \\
\hline 4. Disengaged space & $2(3 \%)$ \\
\hline (a) Kitchen & 2 \\
\hline Total & $63(100 \%)$ \\
\hline
\end{tabular}

\subsection{Impact of space type and interior features on creativity: Informal-group activities}

In all, 44 incidents (specific $=37$, general $=7$ ) concerning informalgroup activities such as social interactions were collected. On average, each participant recalled 0.9 incidents $(S D=0.6$ ) (Table 7). With regard to the outcomes of their informal interactions, a participant said, "It helped get rid of the mind blocks, and helped me feel at ease." In most of these incidents, the participants mentioned the kitchen as the preferred disengaged space for informal gatherings.

Among the supporting interior features, tangible office elements (57 per cent) is the topmost category (Table 8), with the main subcategory being equipment, which refers to the coffee machine as the

TAB LE 7 Space types occupied for "informal-group" activities in the creative work process in the ABOs $(n=50$, total incidents $=44)$

\begin{tabular}{|ll|} 
Categories of spaces & Frequency (\% of total incidents) \\
\hline 1. Disengaged space & $44(100 \%)$ \\
(a) Kitchen & 30 \\
(b) Sofa & 6 \\
(c) Reception & 5 \\
(d) Outdoor & 3 \\
Total & $44(100 \%)$ \\
\hline
\end{tabular}

TAB LE 6 Interior features supporting or hindering "formal-group" creative activities in the ABOs ( $n=50$, total incidents $=63$ )

\begin{tabular}{|c|c|c|c|c|c|}
\hline & \multirow{2}{*}{$\begin{array}{l}\begin{array}{l}\text { Supporting interior } \\
\text { features }\end{array} \\
\text { Category/subcategory }\end{array}$} & \multirow[b]{2}{*}{$\begin{array}{l}\text { Frequency (\% of total supporting } \\
\text { features) }\end{array}$} & & $\begin{array}{l}\text { Hindering interior } \\
\text { features }\end{array}$ & \multirow[b]{2}{*}{$\begin{array}{l}\text { Frequency (\% of total hindering } \\
\text { features) }\end{array}$} \\
\hline & & & & Category/subcategory & \\
\hline 1 & Tangible office elements & $54(52 \%)$ & 1 & Tangible office elements & $31(63 \%)$ \\
\hline (a) & Equipment & $29(28 \%)$ & (a) & Equipment & 15 (31\%) \\
\hline (b) & Furniture & $13(12 \%)$ & (b) & Furniture & $13(26 \%)$ \\
\hline (c) & Decoration and design & $8(7 \%)$ & (c) & Window/view & $3(6 \%)$ \\
\hline (d) & Window/view & $4(5 \%)$ & & & \\
\hline 2 & Spatial layout & $36(34 \%)$ & 2 & Spatial layout & $14(29 \%)$ \\
\hline (d) & Social distraction-free & $4(5 \%)$ & (d) & Space location & $2(4 \%)$ \\
\hline 3 & $\begin{array}{l}\text { Intangible office } \\
\text { elements }\end{array}$ & 15 (14\%) & 3 & $\begin{array}{l}\text { Intangible office } \\
\text { elements }\end{array}$ & $4(8 \%)$ \\
\hline (a) & Light & $6(6 \%)$ & (a) & Air condition & $4(8 \%)$ \\
\hline (b) & Sound level & $4(5 \%)$ & & & \\
\hline (c) & Colour & $3(2 \%)$ & & & \\
\hline \multirow[t]{2}{*}{ (d) } & Air condition & $2(1 \%)$ & & & \\
\hline & Total & 105 (100\%) & & Total & 49 (100\%) \\
\hline
\end{tabular}


most important encouraging factor for meeting up: "Around the coffee machine, it is a good idea to open up."

Among the hindering interior features, tangible office elements (56 per cent) is the topmost category, with lack of/improper furniture as the main subcategory: "I missed having a proper sofa for hangout around the kitchen."

Figure 3 presents the four types of creative activities in the ABOs based on the participants' reports during the CIT interviews in phase 1-it shows how they used the spaces for the different types of activities. In addition, based on the CIT interview findings, Figure 4 presents the interior features significant for each activity type and whether these supported or hindered this process.

\subsection{Observation results}

Figure 5 depicts the total number of activities under the four types conducted in the different spaces based on the observation results of the three cases. These results helped understand the space usage for each activity type and determined the overused and underused spaces mentioned in the interviews as well as their interpretation. In all, 556 activities ( 255 formal-individual, 206 formal-group, 94 informal-group, and only one informal-individual) were recorded. The results show that open spaces (139/255) and private spaces (47/255) were used the most for formal-individual activities. Bookable meeting rooms (193/206) and non-bookable meeting rooms (39/206) were used the most for formal-group activities and virtual meetings. One

TABLE 8 Interior features supporting or hindering "informal-group" activities in the creativity process in the ABOs ( $n=50$, total incidents $=44$ )

\begin{tabular}{|c|c|c|c|c|c|}
\hline & \multirow{2}{*}{$\begin{array}{l}\text { Supporting interior } \\
\text { features }\end{array}$} & \multirow[b]{2}{*}{$\begin{array}{l}\text { Frequency (\% of total supporting } \\
\text { features) }\end{array}$} & & $\begin{array}{l}\text { Hindering interior } \\
\text { features }\end{array}$ & \multirow[b]{2}{*}{$\begin{array}{l}\text { Frequency (\% of total hindering } \\
\text { features) }\end{array}$} \\
\hline & & & & Category/subcategory & \\
\hline 1 & Tangible office elements & $47(57 \%)$ & 1 & Tangible office elements & $5(56 \%)$ \\
\hline (a) & Equipment & 21 (25\%) & (a) & Furniture & $5(56 \%)$ \\
\hline 2 & Spatial layout & 29 (35\%) & 2 & Spatial layout & $2(22 \%)$ \\
\hline (a) & Privacy & 9 (11\%) & (a) & Distraction & $2(22 \%)$ \\
\hline (b) & Openness & $6(7 \%)$ & & & \\
\hline (c) & Space location & $6(7 \%)$ & & & \\
\hline \multirow[t]{2}{*}{ (a) } & Sound-level & $7(8 \%)$ & (a) & Sound-level & $2(22 \%)$ \\
\hline & Total & 83 (100\%) & & Total & $9(100 \%)$ \\
\hline
\end{tabular}

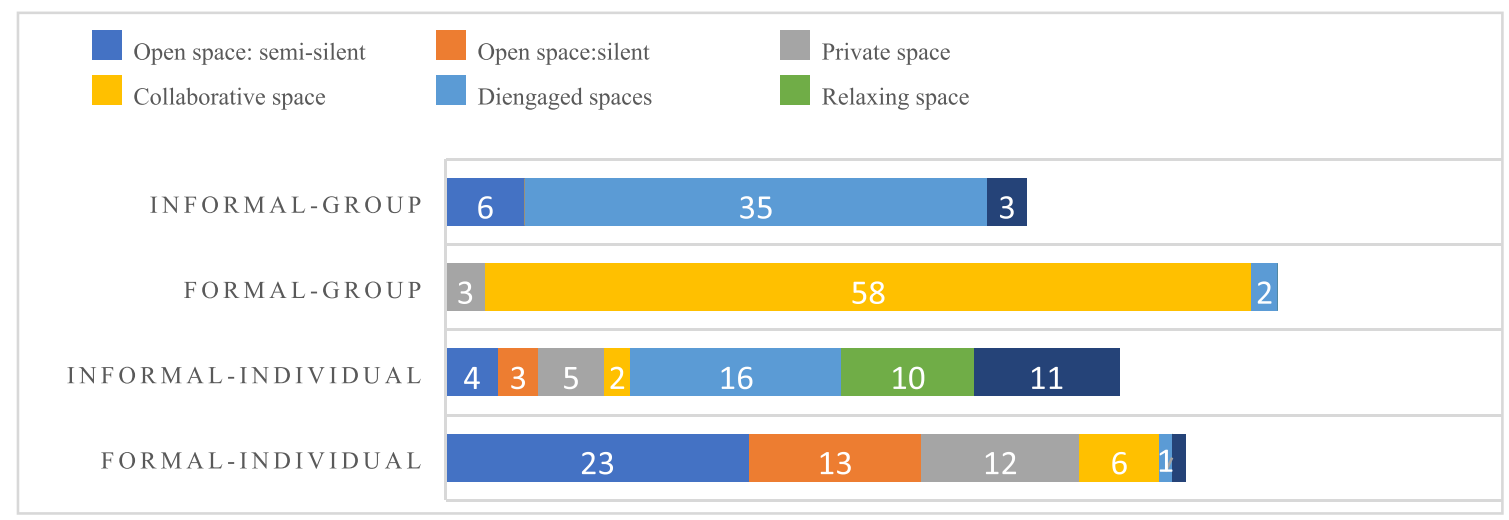

FIGURE 3 Space types occupied during creative activities by the employees $(n=214)$ [Colour figure can be viewed at wileyonlinelibrary. com] 


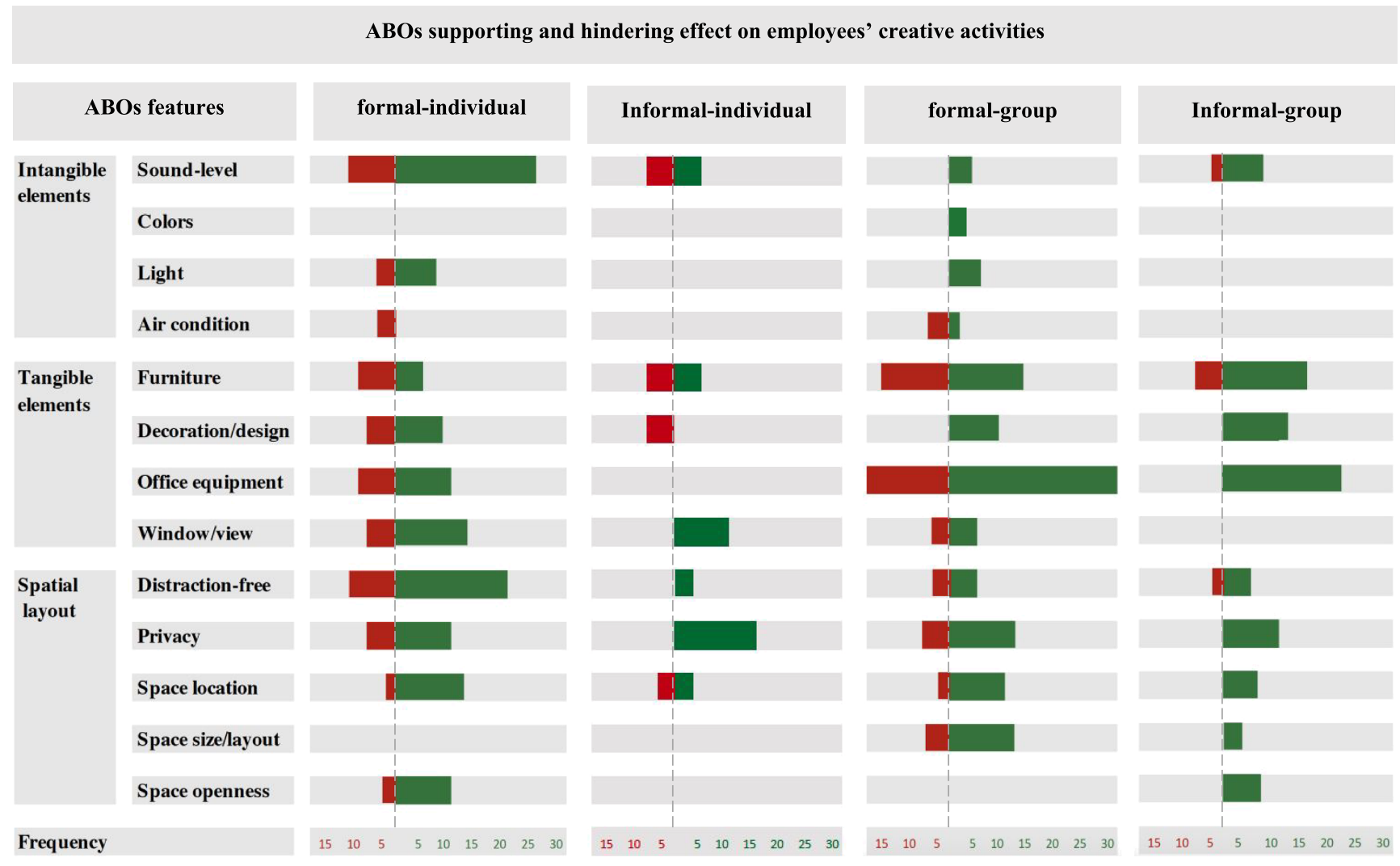

FIGURE 4 ABOs interior features enhancing/hindering creative (a) formal-individual activities, (b) informal-individual activities, (c) formalgroup activities, (d) informal-group activities of employees $(n=50)$ [Colour figure can be viewed at wileyonlinelibrary.com]

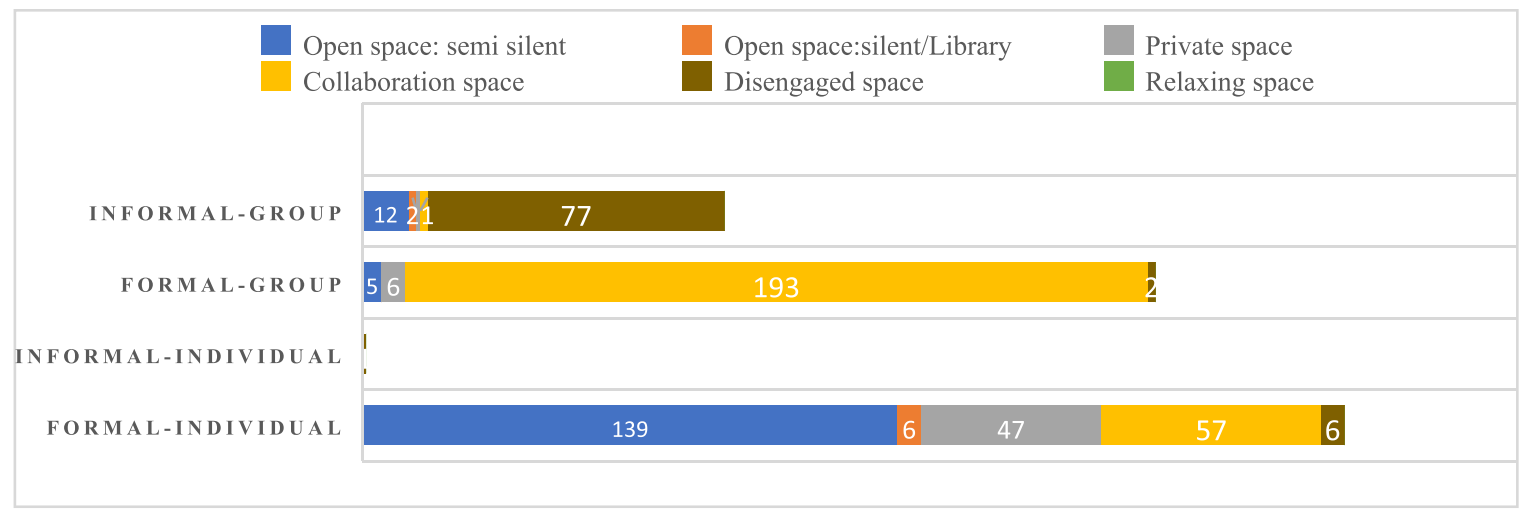

FIG URE 5 Space types occupied during activities based on the 11 rounds observation in three case studies $(n=556)$ [Colour figure can be viewed at wileyonlinelibrary.com]

person was observed sitting alone and relaxing in the kitchen. Finally, 86 of the 94 observations of those meeting up occurred in the kitchen.

Table 9 presents all the types of spaces and detailed interior features found significant in supporting or hindering both individual and group creativity of the participants in the ABOs. These results are based on the integration of the primary data from the CIT interviews and other supplementary sources.

\section{5 | DISCUSSION}

\subsection{Impact of space type and interior features on creative activities in $A B O s$}

The main aim of this study was to explore which types of spaces and interior features in ABOs support and/or hinder formal/informal creative activities at the individual and group levels, and how. We 
TABLE 9 Summary of types of spaces and interior features for each creative activity type

\begin{tabular}{|c|c|c|c|c|c|}
\hline Categories & Elements & \multicolumn{4}{|c|}{ Interior features for each creative activity type } \\
\hline Spaces & Space type & $\begin{array}{l}\text { Open space: } \\
\text { (semi-silent) }^{\mathrm{a}} \\
\text { (silent/library) }^{\mathrm{b}} \\
\text { Private space }^{\mathrm{b}}\end{array}$ & 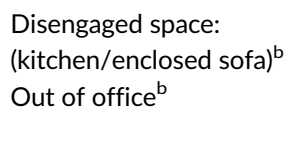 & $\begin{array}{l}\text { Collaborative space: } \\
{\text { (bookable })^{c}}^{(\text {non-bookable })^{b}}\end{array}$ & $\begin{array}{l}\text { Disengaged space: } \\
\text { (kitchen) }^{c} \\
\text { (enclosed sofa) }^{d}\end{array}$ \\
\hline \multirow{2}{*}{$\begin{array}{l}\text { Intangible } \\
\text { office } \\
\text { elements }\end{array}$} & Colours & & -White and grey (cold) & $\begin{array}{l}\text { +Cold: green, blue } \\
\text { +Warm: red }\end{array}$ & \\
\hline & Light & $\begin{array}{l}\text { +Daylight } \\
\text { - Lack of daylight } \\
\text { - Lack of desk light } \\
\text {-Glare }\end{array}$ & & $\begin{array}{l}\text { +Daylight } \\
+ \text { Artificial light }\end{array}$ & \\
\hline \multirow[t]{4}{*}{$\begin{array}{l}\text { Tangible } \\
\text { office } \\
\text { elements }\end{array}$} & Furniture & $\begin{array}{l}\text { +Adjustable furniture } \\
\text {-Ergonomic issues } \\
\text { - Lack of a workstation } \\
\text { - Need for foot supports }\end{array}$ & $\begin{array}{l}\text { +Supports informal } \\
\text { postures/lying down } \\
\text { +Supports postures for } \\
\text { working with laptop } \\
\text {-Leads to improper } \\
\text { working postures } \\
\text { - Not adjustable/ } \\
\text { comfortable }\end{array}$ & $\begin{array}{l}\text { +Adjustable furniture } \\
\text { +Supports postures } \\
\text { +Proper table } \\
\text { +Foot supports } \\
\text { - Not adjustable } \\
\text {-Inflexible/broken wheels } \\
\text { - Round table: Unsupported; } \\
\text { does not face the screen }\end{array}$ & $\begin{array}{l}\text { + Big table } \\
\text { + High back private sofa } \\
\text { +Comfortable chairs } \\
\text { - Unergonomic } \\
\text { furniture }\end{array}$ \\
\hline & $\begin{array}{l}\text { Decoration } \\
\text { and design }\end{array}$ & $\begin{array}{l}+ \text { Closed doors or } \\
\text { partitions } \\
+ \text { Informal/relaxing } \\
\text { - Lack of a sense of } \\
\text { belonging } \\
\text {-Uninviting }\end{array}$ & $\begin{array}{l}\text {-No pictures } \\
\text {-Uncosy design }\end{array}$ & $\begin{array}{l}\text { +Curtains and blinders } \\
+ \text { Enclosed by doors } \\
\text { + Relaxing and cosy }\end{array}$ & $\begin{array}{l}+ \text { Inviting/informal/cosy } \\
\text {-Sterile/too formal }\end{array}$ \\
\hline & & $\begin{array}{l}\text { Low-tech: } \\
\text { +Whiteboard } \\
\text {-Small lockers }\end{array}$ & & $\begin{array}{l}\text { Low-tech: } \\
\text { +Whiteboard } \\
\text {-No whiteboard }\end{array}$ & $\begin{array}{l}\text { Low-tech: } \\
\text { +Newsletters/ } \\
\text { magazines }\end{array}$ \\
\hline & $\begin{array}{l}\text { Window/ } \\
\text { view }\end{array}$ & $\begin{array}{l}\text { +Window/view } \\
+ \text { Transparency } \\
\text {-No window } \\
\text {-No transparency }\end{array}$ & + Window/view & $\begin{array}{l}\text { +Window/view } \\
\text { +Transparency } \\
\text {-No window }\end{array}$ & \\
\hline \multirow[t]{2}{*}{$\begin{array}{l}\text { Spatial } \\
\text { layout }\end{array}$} & $\begin{array}{l}\text { Distraction- } \\
\text { free }\end{array}$ & $\begin{array}{l}\text { +No social distraction } \\
\text {-Social distraction }\end{array}$ & +No social distraction & $\begin{array}{l}\text { +No social distraction } \\
\text {-Social distraction }\end{array}$ & $\begin{array}{l}\text { +Not disturbing others } \\
\text {-Social distraction }\end{array}$ \\
\hline & Privacy & $\begin{array}{l}\text { +Visual/acoustical/data } \\
\text { privacy } \\
\text { - Lack of visual/ } \\
\text { acoustical/data privacy }\end{array}$ & +Visual/general privacy & $\begin{array}{l}\text { +Visual/acoustical/data } \\
\text { privacy } \\
\text { - Lack of visual/acoustical/ } \\
\text { data privacy }\end{array}$ & $\begin{array}{l}+ \text { Visual/acoustical } \\
\text { privacy }\end{array}$ \\
\hline
\end{tabular}


TABLE 9 (Continued)

\begin{tabular}{|c|c|c|c|c|c|}
\hline \multirow[b]{2}{*}{ Categories } & \multirow[b]{2}{*}{ Elements } & \multicolumn{4}{|c|}{ Interior features for each creative activity type } \\
\hline & & Formal-Individual & Informal-Individual & Formal-Group & Informal-Group \\
\hline & $\begin{array}{l}\text { Space } \\
\text { location }\end{array}$ & $\begin{array}{l}\text { +Close to kitchen/ } \\
\text { locker/window } \\
\text { +Corner } \\
\text { - Library in an open area }\end{array}$ & $\begin{array}{l}\text { +Close to kitchen } \\
+ \text { Close to window } \\
\text {-Matter of distance }\end{array}$ & $\begin{array}{l}\text { +Close to kitchen } \\
+ \text { In corners/end of corridors } \\
\text {-Far from other spaces }\end{array}$ & $\begin{array}{l}\text { +Close to kitchen/ } \\
\text { coffee machine } \\
\text { +In the centre }\end{array}$ \\
\hline & $\begin{array}{l}\text { Space size } \\
\text { and layout }\end{array}$ & & & $\begin{array}{l}\text { +Proper size for small/big } \\
\text { meetings/virtual meetings } \\
\text {-Personal distance } \\
\text { - Row layout for co-working }\end{array}$ & $\begin{array}{l}\text { +Proper size of kitchen/ } \\
\text { table/couch }\end{array}$ \\
\hline & $\begin{array}{l}\text { Space } \\
\text { openness }\end{array}$ & $\begin{array}{l}\text { +Open area overlooking } \\
\text { others } \\
\text {-Distracting openness }\end{array}$ & & $\begin{array}{l}\text {-Open space for big } \\
\text { meetings }\end{array}$ & $\begin{array}{l}\text { + No dividing wall } \\
+ \text { Open and visible }\end{array}$ \\
\hline $\begin{array}{l}\mathrm{ABO} \\
\text { policies }\end{array}$ & $\begin{array}{l}\text { Desk- } \\
\text { sharing/ } \\
\text { speech } \\
\text { policies }\end{array}$ & $\begin{array}{l}\text { +Speech policy: silent } \\
\text { zone, supports } \\
\text { concentration } \\
\text {-Silent and active zones } \\
\text { close to each other } \\
\text {-Desk-sharing policy: } \\
\text { private rooms } \\
\text { occupied all day }\end{array}$ & $\begin{array}{l}\text {-Unfitting speech policy } \\
\text { hindered using relaxing } \\
\text { room }\end{array}$ & $\begin{array}{l}\text {-Desk-sharing policy: double } \\
\text { focus rooms occupied by } \\
\text { only one person }\end{array}$ & $\begin{array}{l}\text { +Desk-sharing policy: } \\
\text { more spontaneous } \\
\text { meetings } \\
\text { + Meeting people from } \\
\text { other departments } \\
\text {-Difficult to find } \\
\text { colleagues and weak } \\
\text { social bonds } \\
\text {-Sense of loneliness } \\
\text { and exclusion } \\
\text {-Speech policy: Sofa in } \\
\text { quiet rooms }\end{array}$ \\
\hline
\end{tabular}

Note: + denotes creativity supporting feature; - denotes creativity hindering feature.

a $20-30$ incidents.

b10-20 incidents.

c $30-40$ incidents.

${ }^{\mathrm{d}} 1-10$ incidents.

integrated the results in a three-component model in an attempt to clarify the interaction mechanisms of the physical environment, employee preferences, and creative activities (Figure 6). Contributing to the interactionist perspective, in addition to the $A B O$ environment and creative activities, employee preferences emerged in the results as a component having explanatory power for the interaction between $A B O$ s and creativity. The importance of matching $A B O$ s with employee preferences to improve performance has been mentioned in some studies (e.g., Chafi, 2019; Chafi et al., 2020), but its role as a factor influencing creativity has not been determined. Therefore, this is an important finding in the study of creativity in ABOs. Details of the findings on this topic are discussed below under three different interactions of the physical environment.

\section{Features that continuously support or hinder employees' creativity}

Some features continuously support creativity, such as comfortable, adjustable, and ergonomic furniture (Meinel et al., 2017). This has been overlooked in theory and practice, as ergonomic and adjustable furniture is generally observed to support only formal activities. Thus, our findings add to the existing theory that apparently, employees need adjustable and ergonomic furniture even for informal activities. In the present study, privacy and a distraction-free (control on the level of distraction) environment were also found to be important supporting features for all four types of creative activities. Privacy has also been considered mainly for individual activities (Yekanialibeiglou \& Demirkan, 2018), and in general, the visual and acoustic privacy required for group activities has not been taken into account. This could be due to the lack of research on office context's influence on group creativity (Oldham \& Baer, 2012). A distractionfree environment, which is important for all types of creative activities, is improved after the organization adopts an ABO layout, according to previous studies (Van der Voordt, 2004). Other features that were observed to support all types of creative activities include a cosy and welcoming environment, space location in terms of proximity to the kitchen, and separate spaces based on their noise level and speech policy (Babapour Chafi \& Rolfö, 2019). In contrast, absence/ inadequacy of the above supporting features can hinder employees' creativity (e.g., social distraction and low privacy). Therefore, we found that the mentioned physical features of $A B O$ s have a direct impact on creativity. Dul et al. (2011) also found that the physical environment has a direct influence on individual creativity, but they did not provide details about the interaction between each interior feature and creativity. 


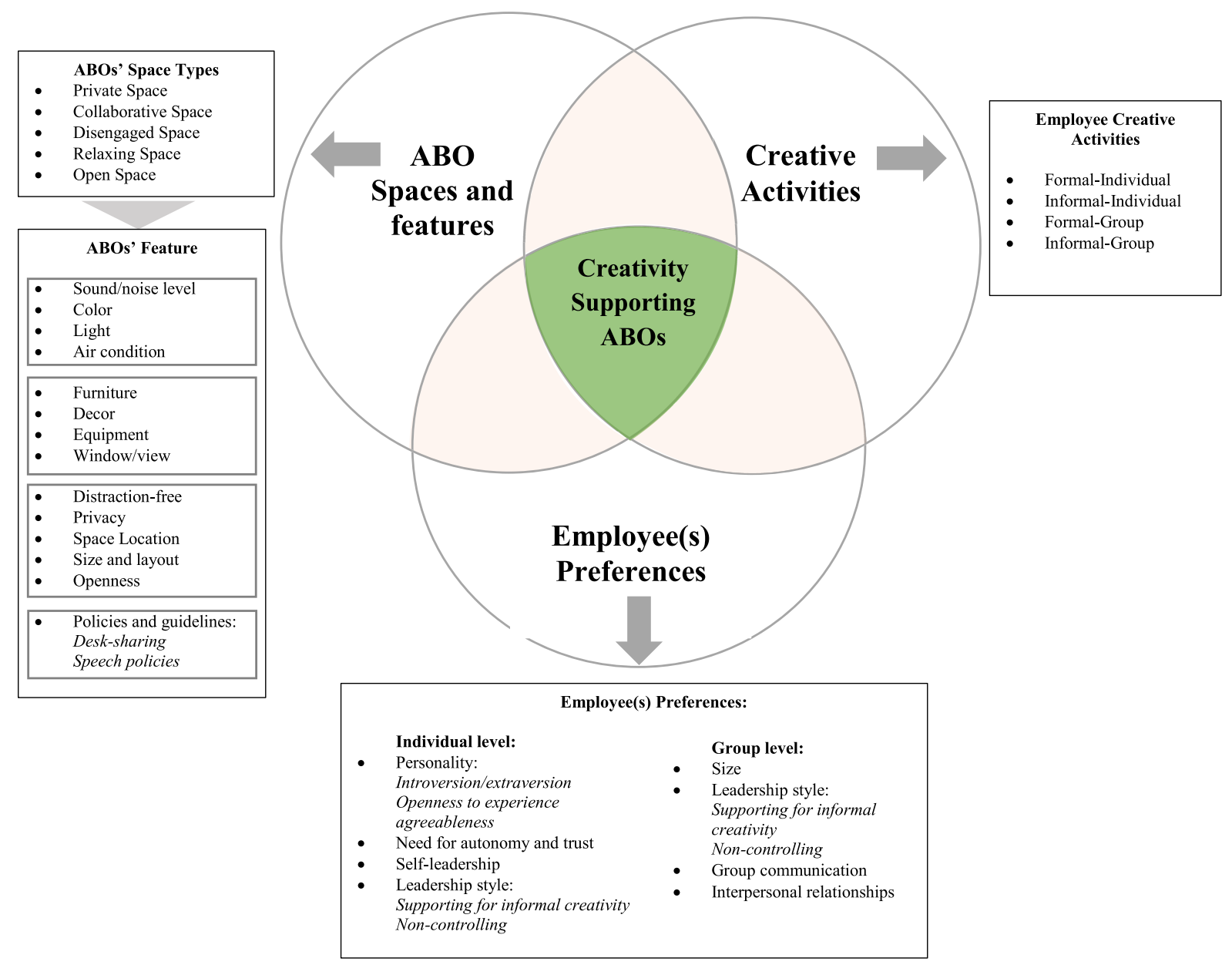

FIGURE 6 The three components of creativity supporting environments [Colour figure can be viewed at wileyonlinelibrary.com]

\section{Features whose effects depend on employee preferences}

Employee preferences seem to play a role in the use of $A B O$ spaces and employee creativity. We found that the same space can be perceived as creativity supporting or hindering, depending on employee preferences. For example, for the same activity type, some employees found too much silence or transparency between spaces supporting, while others found it distracting. This could account for the contradiction in the literature about the effect of open spaces on employee creativity (Hoff \& Öberg, 2015), and it demonstrates the importance of considering the interplay between the employee and environment (Olsson, 2012). In office design research, individual characteristics have been found to affect how employees respond to their environment, thus influencing the relationship between office features and employee performance (Seddigh, 2015). In flexible environments such as ABOs, this response may also manifest itself as employee preferences for the use of a space. Based on our results, at the individual level, personality traits and psychosocial needs, such as extraversion, openness to experience, agreeableness, need for autonomy and trust, self-leadership, and supportive leadership-all of which are important for creativity (Anderson et al., 2014)-can be antecedents to employee space preferences in creative activities. For example, in one case in this study, the participants reacted negatively when their supervisor restricted them to a specific corner of the open space to exert control during their individual activities. This shows how controlling leadership, and lack of freedom and trust can hinder employees from using $A B O$ spaces based on their preferences, and the result of this negative interaction hinders their creativity. In line with these findings, Wohlers and Hertel (2017), in their literature review, concluded that extraversion and agreeableness appear to be the most relevant to employees' reactions towards ABOs. Thus, consistent with the interactionist perspective, we found that creativity flourishes when the $\mathrm{ABO}$ environment, employee psychosocial needs, and personal characteristics are aligned (Woodman et al., 1993).

At the group level, size, supportive leadership, communication, and interpersonal relationship needs can be antecedents to space preferences. For example, one participant reported feeling uncomfortable and distracted by the close personal distance in a meeting room due to poor interpersonal relationships in his group, and that he would prefer a larger room to meet with that group. Thus, interpersonal relationships, which are important for group creativity (Hemlin et al., 2008), may also play a role in employees' preferences in choosing a meeting room. This study adds to the existing theory by highlighting some of employees' characteristics and needs that affect 
their preferences for space usage in $\mathrm{ABO}$, which ultimately affects creativity. A deeper understanding of personality traits and employee needs for using $A B O$ workstations for creative activities is complex and beyond the scope of this study; thus, it should be investigated in future studies.

3. Features whose effects depend on the nature and level of the creative activity

We found some interior features such as pleasant light and fresh air to be important for formal creative activities (both individual and group), but not for informal ones. Consideration of the nature of creative activities (formal and informal) might explain some inconsistencies in the literature on the importance of light for creativity (e.g., Meinel et al., 2017). Considering the importance of pleasant lighting for formal activities, Faria et al. (2017) emphasized that there is no clarity on what constitutes pleasant lighting, but employees understand what would create discomfort. In addition, we found some features to be important depending on the level of creative activities. For example, sufficient physical space and office equipment and facilities were found to be important for group creativity (Lee, 2016), but not necessarily for individual creativity. This could be due to the fact that knowledge workers in CKEs usually tend to work in diverse group sizes, collaborate between groups, and even form new groups (faceto-face, hybrid, or in the digital space) depending on their immediate tasks and location. Therefore, they need fully equipped, adaptable, and appropriately sized spaces to support their flexibility, knowledge sharing, and group creative activities.

Overall, our findings are consistent with those of Evans et al. (Evans et al., 1994, op cit. Leather et al., 2003), who adopted an interactionist perspective for their study and found that any feature of the physical environment can directly influence outcomes and/or interact with psychosocial work elements. Vithayathawornwong et al. (2003) also found that the physical work environment assisted the social work environment in influencing creativity, although they found no direct influence. Our results contrast with those of Dul et al. (2011) who found no interaction between creative personality, socialorganizational features (e.g., teamwork, autonomy, and supportive leadership), and physical features of offices. Moreover, none of these studies examined group creativity. Our findings suggest that $\mathrm{ABO}$ should be carefully designed and implemented to ensure that provision of different types of work environments interacts positively with (1) employees' preferences based on their personalities and needs and (2) employees' creative activity patterns to boost their creativity at the individual and group levels.

\section{2 | Classification of ABOs as creative spaces}

Another issue explored in this study is understanding the potential of $A B O s$ to be classified as creative spaces, which the existing literature does not address. By definition, certain types of spaces and features in office environments that enhance creativity are referred to as creative spaces. In the current study, we examined creativity at individual and group levels based on its formal and informal nature in relation to each major space type and interior features in $A B O s$, which allowed a new perspective in analysing the creativity of flexible offices and provided comprehensive results. The results show that most $A B O$ spaces (except relaxing spaces and open meeting rooms) support at least one of the four types of creative activities. Details of the findings on this aspect are discussed below.

\section{Spaces for formal-individual creativity}

Private and open spaces (semi-silent and silent zones) combined with a distraction-free environment were found to be the most important for supporting individual creative activities. This is consistent with a study by Hoff and Öberg (2015), who found that distracting noise reduces creativity. Offering zones for different noise levels through well-defined policies was found to be an important advantage of ABOs' open spaces in supporting individual creativity, and in this way, the results contribute to existing theory (which focuses on $\mathrm{ABO}$ and creative spaces). The proximity and combination of spaces with different noise levels should be considered to prevent unwanted distractions and hindrance to creativity (Vithayathawornwong et al., 2003). Our finding emphasizing the need for a speech policy for open spaces and layout of spaces based on their noise levels may explain the inconsistency in some studies' findings on concentration in ABOs (e.g., Engelen et al., 2018).

\section{Spaces for informal-individual creativity}

During our observations, we found that relaxing spaces were mostly unoccupied. This finding is not surprising, as some of the previous studies (e.g., Lee, 2016) have reported that relaxing spaces in ABOs do not work as intended. However, the reason for this is not clear in the literature. In this study, we found that the notion of relaxation in the workplace has not yet been fully accepted. This leads to employees having concerns about visibly relaxing during working hours, especially if they do not explicitly receive approval for this from their managers in ABOs. Some participants stated that they need a place in the office to rest and relax for psychological reasons, but they prefer corners not visible to their colleagues. Among other organizational and design factors, a lower openness to experience, lack of freedom, and shying away from new experiences (McCrae, 1987) were mentioned in the interviews as traits responsible for individuals not preferring relaxing rooms for their informal activities. However, studies on relaxing spaces and reasons behind employee preferences for these spaces are limited, and thus, further investigation is required.

\section{Spaces for formal-group creativity}

Office equipment and resources are the most important features of collaborative spaces for supporting group creativity (James \& Drown, 2012) as they facilitate communication and help in developing new ideas (Paulus \& Dzindolet, 2008). Wi-fi access, conferencing, and 
communication software provide an office environment without employees having to be physically present in the office, which suits flexible working (e.g., face-to-face, hybrid, and digital meetings). We found that formal-group activities took place mainly in closed bookable meeting rooms. This is consistent with Lee's (2016) findings. In addition, in our on-site observations, we found that providing additional non-bookable meeting rooms (two to three people) encouraged creative ad hoc meetings and idea sharing-such rooms also ensure that more bookable meeting rooms are available. However, we also found that open collaborative spaces were largely underused and ineffective in supporting creativity. One explanation for this could be the difficulty in sharing confidential data, which hinders knowledge sharing and communication (Babapour Chafi \& Rolfö, 2019)-important processes for group creativity (Hülsheger et al., 2009).

\section{Spaces for informal-group creativity}

We found that disengaged spaces (large kitchen tables serve as a space for big gatherings, small tables with fewer chairs for smaller groups, and semi-enclosed sofas in lounge zones) provide employees with opportunities to share ideas informally and enhance their creativity (De Paoli \& Ropo, 2017; Lee, 2016). Previous studies have found that informal conversations improve relationships and bonding among employees and stimulate idea generation (Damanpour \& Aravind, 2012). The coffee machine was found to be the biggest motivator for employees to gather in disengaged spaces, improving the scope for serendipity in casual meetings (see Steiner, 2006). There were also some grievances about loneliness at the $A B O$ (see also Babapour Chafi \& Rolfö, 2019) and the difficulty of finding colleagues to interact and exchange ideas with (De Been \& Beijer, 2014), which they found to be hindering features for creativity in the current study. In addition, we found that the absence or poor design of disengaged spaces at $A B O$ s may affect employees' psychosocial environment, and this in turn may hinder informal-group activities. Consequently, our results suggest that most spaces (with the exception of relaxation rooms and formal meeting areas in open spaces) in ABOs support creativity and can be classified as creative spaces based on the definition for this study.

\section{6 | CONCLUSION}

\section{1 | Theoretical contribution}

To investigate how $A B O s$ affect individual and group creativity and whether they function as creative spaces for employees, this study adopted an interactionist perspective, which implies that one must consider the interplay between the individual and environment to fully understand creativity. Due to the flexible ways of working in $\mathrm{ABO}$ s and their highly knowledge-intensive environment, this study applied the theoretical framework of CKEs at the micro level to investigate the interactions between knowledge workers, at the individual and group levels, and their $\mathrm{ABO}$ environment. The findings of this study contribute to the interactionist perspective, complement the theoretical framework of CKEs and creative spaces in the following three ways to better understand the role of $A B O s^{\prime}$ physical environment in promoting or inhibiting creativity.

First, the $A B O$ environment has a crucial impact on supporting and hindering individual and group creativity. The main conclusion regarding the role of $A B O$ spaces in individual creativity is that private spaces and quiet zones of open spaces with well-defined speech and desk-sharing policies can be classified as creative spaces.

To support group creativity, the findings indicate that it is important to provide appropriately equipped and furnished non-bookable meeting rooms alongside bookable ones. The CKE framework suggests that certain working styles and spaces in which individuals and groups have high levels of autonomy and self-leadership are crucial for creativity. Based on this study, we note that working in ABOs also requires high levels of autonomy and self-leadership skills. Though social interaction is mentioned as a positive psychosocial antecedent to CKEs, we also note that a desk-sharing policy sometimes makes it difficult for employees to find their colleagues, limiting their interactions and idea exchange.

Second, we note that to support creativity, the $A B O$ environment should appropriately interact with the various preferences of individuals and groups, which is a new finding from the interactionist perspective. Characteristics and needs in individual preferences (e.g., need for autonomy and personality traits such as agreeableness and extraversion) and group characteristics (team size, supportive leadership, etc.) are important components of the CKE framework. We believe that ABOs, when designed by considering employees' actual needs, characteristics, and types of activities have the potential to meet most of these preferences by providing a variety of spaces and functions. Further research in psychological and cognitive studies adopting an interactionist perspective may also help clarify additional predictive individual/group preferences and characteristics and how they interact with various types of spaces and the social environment to influence employee creativity.

Third, this study classifies four types of creative activities (formalindividual, informal-individual, formal-group, and informal-group), which fits well with the flexible concept of $\mathrm{ABO}$ s and creative spaces, and allows a new perspective in studying the interaction between the physical environment and creativity. We found that each activity type is influenced by different environmental characteristics in different ways (supporting/hindering). This study mainly examined idea generation and found that activities aimed at that require different spaces in the office, depending on their nature (formal/informal) and level (individual/group). Therefore, when studying creativity in any office environment, it is important to specify which activity type is being studied.

In conclusion, leveraging the interactionist theory, our study found that a positive interaction between the $A B O$ environment and employees' individual/group preferences and creative activities leads to higher employee creativity. This is a novel contribution to the interactionist theory as there are only a few studies from this perspective with inconsistent results that focus on the traditional physical environment. Another novel finding is that the $A B O$ environment has a greater potential to promote employee creativity than traditional 
offices do, as employees have control over the environment and can change their workstation if it does not suit their preferences or the activity type. This emphasizes choice, flexibility, and personal control in workspaces to accommodate creative tasks. Therefore, ABOs with diverse and flexible spaces that can be reconfigured and adapted to different needs during the creative process can be classified as creative spaces. The CKE framework suggests that the flexibility and fluidity of a nonphysical knowledge-intensive environment can enhance creative efforts. We found that this flexibility should also be applied to the physical environment to enhance creativity. This emphasizes the physical environment's role in organizational creativity theories, a topic that has been researched insufficiently.

\section{2 | Implications for managers}

To improve employees' creativity and performance, it is essential to ensure that they are free to use the spaces in an $A B O$ to their full potential. Supportive and non-controlling managers who promote autonomy and trust are important in CKEs and probably play a central role in how $A B O s$ are used for creative purposes. For example, employees need support when using informal areas such as relaxing spaces, which improves the spontaneous generation of thoughts and ideas. We also found that employees in ABOs with a desk-sharing policy need managerial support when organizing social activities. Such activities are important for employees to expand their social bondsinformal social events bring different teams and departments together, which can improve idea exchange and internal communication, and create so-called weak social ties, all relatively strong predictors of innovation at the organizational level (Damanpour \& Aravind, 2012). Interior designers, facility managers, and consultants are involved in the entire design and construction process of $A B O$ s, but employees, who are the end users of these workplaces, typically are not. One important consideration for managers is to identify employees' preferences and creative requirements by engaging them in the process at the planning and design stages (Doorley \& Witthoft, 2012). Taking into account employees' different preferences is a crucial aspect in designing a creative work environment. Individuals implement their creative thoughts and activities in different ways-some prefer seclusion, while others prefer to have multiple social interactions and feedback from others. This study provides a comprehensive framework that can be employed in practice when firms want to design workspaces to support employees' preferred spaces and features for different types of employee creativity; consequently, the findings could be of interest to an organization as well as consultants and designers who value creativity in office design.

\subsection{Limitations and future research}

This study also has some limitations. Due to its qualitative approach, we could not corroborate our findings with statistical correlations between employee preferences, $A B O$ spaces/features, and creativity.
Future research could supplement this study's qualitative results with a quantitative approach, and draw on the interactionist perspective to evaluate and examine the relationship between employee preferences and perceived creativity-supporting or -hindering features for the four types of creative activities.

Knowing employees' preferences and needs for each activity type, and involving them in the design process of their work environment could influence their perceived support for creativity. However, further studies are needed to investigate this and determine which individual/group characteristics are important for employees' preferences in using $A B O s$ for creative purposes. Future studies adopting an interactionist perspective could also examine additional predictive individual/group characteristics and preferences to determine how they interact with $A B O$ physical and nonphysical features to influence employee creativity.

In this study, three companies in Sweden were investigated. We argue that because of the representative sample of knowledge workers with approximately equal proportions of men and women and an average age of 42 , the results can be reasonably transferred to other knowledge-intensive institutions using ABOs. However, a larger data set, collected in different countries with different work cultures, will increase the generalizability of the conclusions and cross-validate the findings. Country culture and organizational culture might influence creativity (Hemlin et al., 2008) through space use, employee preferences, and leadership style in ABOs.

Another limitation of our study was that the interviews were conducted in English, which was the second language of most of the participants. However, since all three cases were international companies, the participants spoke English during parts of their workday. There were no major communication problems during the interviews; however, the pace of the interviews was relatively slow.

Only one author was involved in coding-according to the literature, most qualitative studies have only one coder, and if an intercoder reliability test is satisfactory, the primary researcher can continue coding the rest of the data alone. For this study, an additional person was asked to code 15 per cent of the data, and the intercoder reliability was sufficient (O'Connor \& Joffe, 2020).

\section{ACKNOWLEDGEMENTS}

This study is conducted as a part of PhD thesis of the first author in i. D. Bilkent University, in the Department of Interior Architecture and Environmental Design. The authors would like to thank Prof. Dr. Deniz Hasırcı İnceoğlu and Assoc. Prof. Dr. Yasemin Afacan for their valuable contributions at all stages of this study.

The authors received no specific funding for this work.

\section{DATA AVAILABILITY STATEMENT}

The authors confirm that the derived data supporting the findings of this study are available upon reasonable request from the corresponding author [SY].

\section{ORCID}

Sepideh Yekanialibeiglou (D) https://orcid.org/0000-0002-0450-5132 


\section{REFERENCES}

Amabile, T. M., Conti, R., Coon, H., Lazenby, J., \& Herron, M. (1996). Assessing the work environment for creativity. Academy of Management Journal, 39(5), 1154-1184.

Anderson, N., Potočnik, K., \& Zhou, J. (2014). Innovation and creativity in organizations: A state-of-the-science review, prospective commentary, and guiding framework. Journal of Management, 40(5), 1297-1333. https://doi.org/10.1177/0149206314527128

Appel-Meulenbroek, R., Groenen, P., \& Janssen, I. (2011). An end-user's perspective on activity-based office concepts. Journal of Corporate Real Estate, 13(2), 122-135. https://doi.org/10.1108/ 14630011111136830

Babapour Chafi, M., \& Rolfö, L. (2019). Policies in activity-based flexible offices-'I am sloppy with clean-desking. We don't really know the rules.'. Ergonomics, 62(1), 1-20. https://doi.org/10.1080/00140139. 2018.1516805

Batey, M., Hughes, D. J., Crick, L., \& Toader, A. (2021). Designing creative spaces: An experimental examination of the effect of a nature poster on divergent thinking. Ergonomics, 64(1), 139-146.

Bitner, M. J., Booms, B. H., \& Tetreault, M. S. (1990). The service encounter: Diagnosing favorable and unfavorable incidents. Journal of Marketing, 54(1), 71-84.

Blok, M., Groenesteijn, L., Schelvis, R., \& Vink, P. (2012). New ways of working: Does flexibility in time and location of work change work behavior and affect business outcomes? Work (Reading, Mass.), 41(Suppl. 1), 2605-2610. https://doi.org/10.3233/WOR2012-1028-2605

Braun, V., \& Clarke, V. (2006). Using thematic analysis in psychology. Qualitative Research in Psychology, 3, 77-101. https://doi.org/10.1191/ 1478088706qp063oa

Brophy, D. R. (1998). Understanding, measuring, and enhancing individual creative problem-solving efforts. Creativity Research Journal, 11(2), 123-150.

Campbell, J. L., Quincy, C., Osserman, J., \& Pedersen, O. K. (2013). Coding in-depth semistructured interviews: Problems of unitization and intercoder reliability and agreement. Sociological Methods \& Research, 42, 294-320. https://doi.org/10.1177/0049124113500475

Canestrari, A. S., \& Marlowe, B. A. (Eds.) (2018). The Wiley international handbook of educational foundations. John Wiley \& Sons.

Chafi, M. B. (2019). The quest for the room of requirement: Why some activity-based flexible offices work while others do not [Doctoral dissertation]. Chalmers Tekniska Hogskola.

Chafi, M. B., Harder, M., \& Danielsson, C. B. (2020). Workspace preferences and non-preferences in activity-based flexible offices: Two case studies. Applied Ergonomics, 83, 102971. https://doi.org/10.1016/j. apergo.2019.102971

Creswell, J. W. (2013). Research design. Qualitative, quantitative and mixed method approaches (3rd ed.). Sage.

Damanpour, F., \& Aravind, D. (2012). Organizational structure and innovation revisited: From organic to ambidextrous structure. In Handbook of organizational creativity (pp. 483-513). Academic Press.

De Been, I., \& Beijer, M. (2014). The influence of office type on satisfaction and perceived productivity support. Journal of Facilities Management, 12(2), 142-157. https://doi.org/10.1108/JFM-02-20130011

De Been, I., Beijer, M., \& den Hollander, D. (2015). How to cope with dilemmas in activity-based work environments: Results from usercentred research. In 14th EuroFM Research Symposium (pp. 1-10) Glasgow.

De Paoli, D., \& Ropo, A. (2017). Creative workspaces-A fad or making real impact? Journal of Corporate Real Estate.

Denscombe, M. (2014). The good research guide: For small-scale social research projects. McGraw-Hill Education.

Doorley, S., \& Witthoft, S. (2012). Make space: How to set the stage for creative collaboration. John Wiley \& Sons.
Dul, J., Ceylan, C., \& Jaspers, F. (2011). Knowledge workers' creativity and the role of the physical work environment. Human Resource Management, 50(6), 715-734. https://doi.org/10.1002/hrm.20454

Engelen, L., Chau, J., Young, S., Mackey, M., Jeyapalan, D., \& Bauman, A. (2018). Is activity-based working impacting health, work performance and perceptions? A systematic review. Building Research \& Information, 47(4), 468-479. https://doi.org/10.1080/09613218.2018.1440958

Evans, G. W., Johansson, G., \& Carrere, S. (1994). Psychosocial factors and the physical environment: Inter-relations in the workplace. In C. Cooper \& I. Robertson (Eds.), Review of industrial and organizational psychology (Vol. 9) (pp. 1-30). Wiley.

Faria, J. R. G. D., Inskava, A. Y., \& Planitzer, S. T. (2017). Lighting preferences in individual offices. Ambiente Construído, 17(1), 39-53. https:// doi.org/10.1590/s1678-86212017000100122

Feist, G. J. (1998). A meta-analysis of personality in scientific and artistic creativity. Personality and Social Psychology Review, 2(4), 290-309. https://doi.org/10.1207/s15327957pspr0204_5

Flanagan, J. C. (1954). The critical incident technique. Psychological Bulletin, 51, 327-358.

Hemlin, S., Allwood, C. M., \& Martin, B. R. (2008). Creative knowledge environments. Creativity Research Journal, 20(2), 196-210. https://doi. org/10.1080/10400410802060018

Hoendervanger, J. G., Ernst, A. F., Albers, C. J., Mobach, M. P., \& Van Yperen, N. W. (2018). Individual differences in satisfaction with activity-based work environments. PLoS ONE, 13(3), e0193878.

Hoff, E. V., \& Öberg, N. K. (2015). The role of the physical work environment for creative employees: A case study of digital artists. The International Journal of Human Resource Management, 26(14), 1889-1906. https://doi.org/10.1080/09585192.2014.971842

Hughes, H., Williamson, K., \& Lloyd, A. (2007). Critical incident technique. Exploring Methods in Information Literacy Research, 28, 49-66.

Hülsheger, U. R., Anderson, N., \& Salgado, J. F. (2009). Team-level predictors of innovation at work: A comprehensive meta-analysis spanning three decades of research. Journal of Applied Psychology, 94(5), 1128. https://doi.org/10.1037/a0015978

llozor, B. D., Love, P. E. D., \& Treloar, G. (2002). The impact of work settings on organisational performance measures in built facilities. Facilities, 20(1), 61-67.

James, K., \& Drown, D. (2012). Organizations and creativity: Trends in research, status of education and practice, agenda for the future. In Handbook of organizational creativity (pp. 17-38). Academic Press.

Klein, K. J., \& Sorra, J. S. (1996). The challenge of innovation implementation. Academy of Management Review, 21(4), 1055-1080. https://doi. org/10.5465/amr.1996.9704071863

Leather, P., Beale, D., \& Sullivan, L. (2003). Noise, psychological stress and their interaction in the workplace. Journal of Environmental Psychology, 23, 213-222.

Lee, Y. S. (2016). Creative workplace characteristics and innovative startup companies. Facilities, 34(7/8), 413-432. https://doi.org/10.1108/ F-06-2014-0054

Lombard, M., Snyder-Duch, J., \& Bracken, C. C. (2002). Content analysis in mass communication: Assessment and reporting of intercoder reliability. Human Communication Research, 28(4), 587-604.

McCrae, R. R. (1987). Creativity, divergent thinking, and openness to experience. Journal of Personality and Social Psychology, 52(6), 1258. https://doi.org/10.1037/0022-3514.52.6.1258

Meinel, M., Maier, L., Wagner, T. F., \& Voigt, K. I. (2017). Designing creativity-enhancing workspaces: A critical look at empirical evidence. Journal of Technology and Innovation Management, 1(1).

Merriam, S. B. (2009). Qualitative research: A guide to design and implementation (3rd ed.). Jossey-Bass.

Mumford, M. D., Scott, G. M., Gaddis, B., \& Strange, J. M. (2002). Leading creative people: Orchestrating expertise and relationships. The Leadership Quarterly, 13(6), 705-750. https://doi.org/10.1016/S1048-9843 (02)00158-3 
Nanayakkara, K. T., Wilkinson, S. J., \& Ghosh, S. (2021). Future office layouts for large organisations: Workplace specialist and design firms' perspective. Journal of Corporate Real Estate.

O'Connor, C., \& Joffe, H. (2020). Intercoder reliability in qualitative research: Debates and practical guidelines. International Journal of Qualitative Methods, 19, 1609406919899220. https://doi.org/10. $1177 / 1609406919899220$

Oldham, G. R., \& Baer, M. (2012). Creativity and the work context. In Handbook of organizational creativity (pp. 387-420). Academic Press.

Oldham, G. R., Cummings, A., \& Zhou, J. (1995). The spatial configuration of organizations: A review of the literature and some new research directions. Research in Personnel and Human Resource Management, 13(1-37).

Olsson, L. (2012). Leadership and creativity in research: Investigations of leadership and leader-member exchange (LMX) in research groups.

Paletz, S. B. (2012). Project management of innovative teams. In Handbook of organizational creativity (pp. 421-455). Academic Press.

Paulus, P. B., \& Dzindolet, M. (2008). Social influence, creativity and innovation. Social Influence, 3(4), 228-247. https://doi.org/10.1080/ 15534510802341082

Paulus, P. B., Dzindolet, M., \& Kohn, N. W. (2012). Collaborative creativity-Group creativity and team innovation. In Handbook of organizational creativity (pp. 327-357). Academic Press. https://doi.org/10. 1016/B978-0-12-374714-3.00014-8

Pitta, D. A., Wood, V. R., \& Franzak, F. J. (2008). Nurturing an effective creative culture within a marketing organization. Journal of Consumer Marketing, 25(3), 137-148. https://doi.org/10.1108/ 07363760810870635

Robertson, M. M., Huang, Y.-H., O'Neill, M. J., \& Schleifer, L. M. (2008). Flexible workspace design and ergonomics training: Impacts on the psychosocial work environment, musculoskeletal health, and work effectiveness among knowledge workers. Applied Ergonomics, 39(4), 482-494. https://doi.org/10.1016/j.apergo.2008.02.022

Rolfö, L. (2018). Activity-based flexible office work environments: Design and implementation processes and outcomes [Doctoral dissertation]. KTH Royal Institute of Technology.

Seddigh, A. (2015). Office type, performance and well-being: A study of how personality and work tasks interact with contemporary office environments and ways of working [Doctoral dissertation]. Department of Psychology, Stockholm University.

Serenko, A. (2006). The use of interface agents for email notification in critical incidents. International Journal of Human-Computer Studies, 64(11), 1084-1098. https://doi.org/10.1016/j.ijhcs.2006.06.004

Steiner, G. (2006). Innovative performance of organizations as a result of their physical environment. XVIth World Congress on Sociology, "The Quality of Social Existence in a Globalistic World", Durban, South Africa, July 23-29, 2006.

Stokols, D., Clitheroe, C., \& Zmuidzinas, M. (2002). Qualities of work environments that promote perceived support for creativity. Creativity Research Journal, 14(2), 137-147.

Tabak, V. (2009), "User simulation of space utilisation: System for office building usage simulation" [PhD dissertation]. Eindhoven University of Technology, Eindhoven.

Thoring, K., Desmet, P., \& Badke-Schaub, P. (2018). Creative environments for design education and practice: A typology of creative spaces. Design Studies, 56, 54-83. https://doi.org/10.1016/j.destud.2018. 02.001

van den Berg, J., Appel-Meulenbroek, R., Kemperman, A., \& Sotthewes, M. (2020). Knowledge workers' stated preferences for important characteristics of activity-based workspaces. Building Research \& Information, 48(7), 703-718. https://doi.org/10.1080/09613218.2020.1726169

Van der Voordt, T. J. M. (2004). Productivity and employee satisfaction in flexible workplaces. Journal of Corporate Real Estate, 6(2), 133-148.

Vithayathawornwong, S., Danko, S., \& Tolbert, P. (2003). The role of the physical environment in supporting organizational creativity. Journal of
Interior Design, 29(1-2), 1-16. https://doi.org/10.1111/j.1939-1668. 2003.tb00381.x

Ward, T. B. (2012). Problem solving. In Handbook of organizational creativity (pp. 169-187). Academic Press.

Wensley, A. (1998). The value of story telling. Knowledge and Process Management, 5(1), 1-2. https://doi.org/10.1002/(SICI)1099-1441(199803) 5:1<1::AID-KPM14>3.0.CO;2-X

Wohlers, C., \& Hertel, G. (2017). Choosing where to work at worktowards a theoretical model of benefits and risks of activity-based flexible offices. Ergonomics, 60(4), 467-486. https://doi.org/10.1080/ 00140139.2016.1188220

Woodman, R. W., Sawyer, J. E., \& Griffin, R. W. (1993). Toward a theory of organizational creativity. Academy of Management Review, 18(2), 293321. https://doi.org/10.5465/amr.1993.3997517

Yekanialibeiglou, S., \& Demirkan, H. (2018). Enhancing creative performance in work environments. In DS 89: Proceedings of The Fifth International Conference on Design Creativity (ICDC 2018), University of Bath, Bath, UK (pp. 264-271).

Yin, R. K. (2018). Case study research and applications: Design and methods. SAGE Publications.

Zhou, J., \& Hoever, I. J. (2014). Research on workplace creativity: A review and redirection. Annual Review of Organizational Psychology and Organizational Behavior, 1(1), 333-359.

\section{AUTHOR BIOGRAPHIES}

Sepideh Yekanialibeiglou received her PhD from the Department of Interior Architecture and Environmental Design at Bilkent University. Her main research interest is in the field of Environmental Psychology. Her doctoral research, Influence of Activity-Based Office Environments on Perceived Individual and Group Creativity, was conducted in two phases to find the relationship between $A B O s$, employee creativity and the concept of creative spaces and also to identify and investigate mediating variables in this relationship. Sepideh was a visiting researcher at the Department of Psychology, University of Gothenburg, during the last years of her doctoral studies and conducted the main data collection for her dissertation in five international companies in Sweden (e-mail: sepideh@bilkent.edu.tr).

Halime Demirkan is a Professor of Architecture in the Department of Interior Architecture and Environmental Design at i. D. Bilkent University, Turkey. Her research interests include creativity, architectural design, design education, and human factors in design. She has published more than 40 peer-reviewed articles and many book chapters. She received her MS and BS in Industrial Engineering and $\mathrm{PhD}$ in Architecture at Middle East Technical University (e-mail: demirkan@bilkent.edu.tr).

Leif Denti received his PhD from the university of Gothenburg. His main research venue is leaders' influence on creativity and innovation in R\&D project teams. In his dissertation, Leadership and Innovation in R\&D Teams, he studied R\&D projects across five major industrial corporations situated in four countries. Leif Denti is a senior lecturer at the Department of Psychology, University of Gothenburg. He is also a visiting lecturer at Chalmers University of Technology. He is a jury-member of the national 
award Manager of the Year, staff writer at innovationmanagement.se and founder of the Swedish innovation dissemination website tusentips.se. Currently, Leif is engaged in several state-funded action research projects directed towards increasing the innovation capabilities of the Swedish innovation system, on both the employee level and the top management level (e-mail: leif.denti@gu.se).
How to cite this article: Yekanialibeiglou, S., Demirkan, H., \& Denti, L. (2021). Enhancing creativity in activity-based offices: A critical incident study of knowledge workers. Creativity and Innovation Management, 30(4), 763-782. https://doi.org/10. 1111/caim.12464 